\section{Wiley Guide to Chemical Incompatibilities}

by Richard P. Pohanish and Stanley

A. Greene (Eds): Wiley, Weinheim, Germany, 3rd ed., 2009, pp 1110, ISBN: 978-0-470-38763-4.

Price: EUR 145.90, GBP 117.00

Originally published in compact form in 1997, a second expanded edition followed in 2002. This third edition represents a further updated and significant expansion compared to the second edition. There are 250 new entries, 9,000 new chemical incompatibility profiles, and all previously published chemical incompatibility profiles have been rewritten. Additional data have been added at all levels, including more flash point data, molecular formulas, lower and upper explosive limits, auto-ignition temperatures, NPFA-type numerical fire codes, recommended fire extinguishing media and the dangerous thermal decomposition products that may be released in a fire. The term incompatibility is used to describe the total range of reactions that might occur: self-ignition caused by contact with air or moisture; auto-decomposition; auto-generation of toxic gases; the heating, overflow or rupture of containers; polymerisation; fire; detonation; explosion; the formation of new and possibly more dangerous compounds; reactions with other compounds or any of the above in combination. The result is a weighty tome that will supplement that other indispensible reference "bible", the Handbook of Chemistry and Physics. Where previously the Handbook needed a diligent search to obtain specific safety data, this can now be accessed more readily and quickly from the Guide.

Although every chemical is shipped with a material safety data sheet (MSDS) on its use, handling and storage, with critical information about known toxicology and health hazards, transportation, first response, storage and dispersal, MSDSs cannot in themselves be complete and are not always appropriate for some specific chemical use. Even this extensive list of most of the 3,000 high production volume chemicals used around the world cannot begin to cover the several hundreds of thousands of chemicals listed for example by the Chemical Abstract service of the American Chemical Society.

Although of primary reference interest to practicing chemists, there is a much wider potential readership; the fire services, police, emergency first responders, or any public sector body that may be called out to almost any form of accident involving chemical spillage. All these services would be expected to have reasonable training in chemical recognition and terminology, but almost certainly they would be forced into using trivial names or initials rather than their full chemical name.

By selecting a few common chemicals, and assuming hypothetical emergencies, it proved to be quick, easy and surprisingly accurate to get to an appropriate heading that would deal with the particular imagined emergency. This manual will work best for trained chemists, but it also worked well for those with more limited knowledge. This is an essential reference book for anyone dealing with emergency situations involving chemicals.

K. Jones 